\title{
DE LA COMUNIDAD FORMATIVA A LA FRATERNIDAD SACERDOTAL
}

DOI: https://doi.org/10.52039/seminarios.v55i194.455

Lope RuBio Parrado 1

ÍNDICE

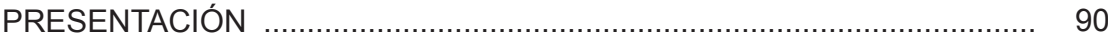

1. PUNTOS DE PARTIDA: ............................................................... 92

1.1. Pastores dabo vobis (PDV), punto central de partida .................. 92

1.2. Otros documentos ..................................................................... 94

1.3. Definición de Seminario y de Formación Permanente .................. 95

1.4. Tema reiterativo en los años postconciliares ............................... 96

2. INTERROGANTES ....................................................................... 100

2.1. ¿Dónde colocar el límite entre Formación Inicial y Formación

Permanente? .............................................................................. 100

2.2. ¿Pueden los seminarios responder a las exigencias formativas que posibiliten una incorporación natural en la Formación Permanente? ... 101

3. DE LA COMUNIDAD FORMATIVA A LA FRATERNIDAD SACERDOTAL 102

3.1. Iniciación a la sensibilidad del Pastor ........................................... 103

3.2. Preparar para realizar una pastoral comunitaria .......................... 105

3.3. Para incorporarse a una Iglesia Particular. Sentido de pertenencia 107

3.4. Sentido de la comunidad eclesial, orgánica y universal ................ 108

3.5. Conocer las distintas formas de asociación sacerdotal, siempre dentro de la única Iglesia y del único presbiterio ............................... 110

3.6. Algunos acentos de la espiritualidad a desarrollar en la formación espiritual durante la estancia en el Seminario .............. 112

3.6.1. Formar/preparar para una espiritualidad de comunión . 112

3.6.2. Formar para una espiritualidad de la Caridad Pastoral . 113

3.7. Preparar para ser sacerdotes fieles ....................................... 116

3.8. Preparar para acompañar y dejarse acompañar ......................... 118

3.9. Preparar para situarse siempre como discípulos ........................ 120

4. NOTAS PARA UN PROYECTO DE FORMACIÓN CONTINUADA ......... 121

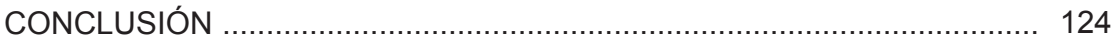

1 Es sacerdote operario diocesano. Ha sido director general de la Hermandad y en los años de servicio en ese cargo estimuló la creación de institutos de pastoral vocacional en Buenos Aires, México, Caracas, Washington y Sâo Paulo. Ha sido rector del Pontificio Colegio Español de san José en Roma a lo largo de 14 años y actualmente es profesor del bienio de licenciatura en el departamento de Espiritualidad y Formación de las vocaciones de la facultad de Teología de la Universidad Pontificia de México. Reside en Roma. 
El Seminario es sobre todo una comunidad educativa en camino... La identidad profunda del Seminario es la de ser, a su manera, una continuación en la Iglesia, de la única comunidad apostólica formada en torno a Jesús en la escucha de la Palabra, en camino hacia la experiencia Pascual (PDV, 61).

Los presbíteros están unidos todos entre sí por la íntima FRATERNIDAD SACRAMENTAL, y forman un presbiterio especial en la diócesis a cuyo servicio se consagran bajo el obispo propio (PO, 8).

\section{PRESENTACIÓN}

El papa Benedicto XVI abrió el Año Sacerdotal con las Vísperas celebradas en la basílica de San Pedro en el Vaticano en la tarde del 19 de Junio de 2009, solemnidad del Sagrado Corazón de Jesús. Lo había convocado en su carta del 16 de Junio dirigida a los queridos hermanos en el sacerdocio, con ocasión del 150 aniversario de la muerte de San Juan María Vianney y con el lema: Fidelidad de Cristo. Fidelidad del Sacerdote.

La Congregación para el Clero, en comunicación con las Conferencias Episcopales y los superiores de los Institutos de Vida Consagrada están promoviendo diversas iniciativas espirituales y pastorales que concluirán con el encuentro mundial sacerdotal a celebrarse en Roma en Junio de 2010 con el que se clausurará el Año Sacerdotal. La Congregación desea que todo ello

sirva para hacer que se perciba cada vez más la importancia del papel y la misión del sacerdote en la Iglesia y en la sociedad contemporánea, así como potenciar la formación permanente de los sacerdotes vinculándola a la de los seminaristas.

Este es justamente nuestro tema. La unión que debe existir en un proyecto formativo integral entra la etapa llamada Inicial y la Permanente. La Pontificia Comisión para América Latina, en el documento conclusivo de la Asamblea Plenaria celebrada en Febrero de 2009, refiriéndose a los formadores de los futuros pastores, dice que

El padre rector, los directores espirituales y demás formadores vivan este carisma en un contexto de formación permanente como discípulos y misioneros (II).En la conclusión añaden que: dicha formación permanente, debe ser impulsada ya desde la vida misma del Seminario ${ }^{2}$.

2 Texto íntegro en L'Osservatore Romano. Ed. En lengua española, 7 al 13 de marzo, 2009, 11-13. 
San Juan de Ávila, maestro universal de espiritualidad sacerdotal, en el Memorial Primero al Concilio de Trento (1551) escribía:

Y pues prelados con clérigos son como padres con hijos y no seño-
res con esclavos, prevéanse el papa, y los demás en criar a los
clérigos como a hijos, con aquel cuidado que pide una dignidad tan
alta como han de recibir; y entonces tendrán mucha gloria en tener
hijos sabios y mucho gozo y descanso en tener hijos buenos, y
gozarse ha toda la Iglesia con buenos ministros.

Pues sea esta la conclusión; que de orden y manera para educarlos que sean tales; $y$ que es menester tomar el negocio de más atrás, y tener por cosa cierta que, si quiere la Iglesia tener buenos ministros, que conviene hacellos; y, si quiere tener gozo de buenos médicos de almas, ha de tener a su cargo de los criar tales y tomar trabajo en ello; y si no, no alcanzará lo que desea_(nn 5 y 9). Más adelante les recomendará: $Y$ aprendan principalmente bondad $y$ después letras, para que puedan ser sin peligro maestros y edificadores de almas (n.12)... Mas todo se puede tener por bien empleado por sacar hombres que sean luz del mundo, y sal de la tierra, y gloria de Cristo (n 15) ${ }^{3}$.

Tomar el negocio de atrás. Desde el comienzo. Desde el Seminario si se quiere tener buenos ministros. Creo que el Patrono del clero español apunta claramente a la formación continuada. PDV define el Seminario como una comunidad educativa en camino (n.60), y a los presbíteros como Una representación sacramental de Jesucristo Cabeza y Pastor (n.15).

El Concilio Vaticano II, aplicando el concepto de colegialidad a los presbíteros, declara que

el presbitero tiene una estructura esencialmente colegial, fundada en la fraternidad sacramental, unidos todos entre sí por la íntima fraternidad del sacramento $(\mathrm{PO}, 8)$. Todos los presbiteros, en virtud de la común ordenación sagrada y de la común misión, están íntimamente unidos entre sí como hermanos (LG, 28).

La cuestión que planteamos, desde el ámbito de la formación permanente, es cómo dar el paso de la comunidad educativa/formativa del seminario a la fraternidad sacramental/presbiteral. Qué debe y puede hacer el seminario para capacitar a los alumnos a dar ese salto cualitativo ya que la misma exhortación PDV indica que la formación inicial y la formación permanente deben ser atendidas, sin olvidar nunca la profunda relación que tienen entre sí y que debe hacer de las dos un solo proyecto orgánico de vida cristiana y sacerdotal (n.42).

3 Obras Completas, II BAC,2001, pp.487,490492 y 494. 


\section{PUNTOS DE PARTIDA}

Indicamos dos textos que de alguna forma nos sirvan de punto de partida y de llegada al mismo tiempo. En primer lugar releamos el de OT, 8 en el que se nos dice que: La formación sacerdotal...debe continuarse y perfeccionarse incluso una vez terminado el ciclo de estudios en los seminarios.

Esto decían los padres conciliares en octubre de 1965. En el documento de la $V$ Conferencia el Episcopado Latinoamericano del Caribe, en mayo de 2007, leemos: es oportuno señalar la complementariedad entre la formación inicial en el seminario y el proceso formativo, que abarca las diversas etapas de la vida del presbitero. Hay que despertar la conciencia de que la formación sacerdotal termina con la muerte. Y después de subrayar la importancia de la formación para los sacerdotes jóvenes a tenor de PDV 76, añade: Al respecto, se requieren proyectos diocesanos bien articulados y constantemente evaluados 4 .

Cuarenta y dos años separan estos dos textos. Pero entre uno y otro han pasado por el cauce de la historia de la sociedad y de la vida de la Iglesia acontecimientos que hacen que el incluso de OT se haya convertido en la afirmación de que la formación solo termina con la muerte.

\subsection{PDV, punto central de partida}

Podemos decir que el punto central del tema lo encontramos en la exhortación apostólica PDV, puesto que hace un llamado a promover un desarrollo nuevo y orientador del tema de la formación antes y después de la ordenación sacerdotal.

Por otra parte, desde que se acuñó por primera vez el término de Educación Permanente en la reunión de la UNESCO celebrada en Montreal en 1960 y la consagración de la expresión Formación Permanente en la exhortación PDV de 1992 se ha producido un cambio sustancial en la forma de entender los términos. En efecto, incluso en as esferas laicas se indica que es preciso comprender el hombre bajo una luz nueva, superando los ritmos y los tiempos tradicionales de la educación: la educación básica, la educación profesional y la educación permanente 5 .

La educación se convierte en algo sustancial a la existencia humana, haciéndose presente en todos los momentos de la vida: la educación/formación sin límites temporales se transforma en una dimensión de la vida misma. Las edades se suceden, los contenidos se enriquecen, los proyectos

4 Documento de Aparecida, n.326

5 Cfr. el Informe de la UNESCO de 1996 
varían según los diversos destinatarios; pero las dimensiones constitutivas de la persona, seminarista primero y presbítero después, permanecen.

Por ello, en perfecta sintonía con PDV, podemos hablar de una formación para el que va a ser presbítero y de una formación en el ejercicio del ministerio. Pero siendo bien conscientes de que esta vivisección la hacemos solo para su estudio pues la persona es una y única.

Ya hemos indicado que este es el principio que nos legitima para hacernos la pregunta anteriormente formulada: ¿Qué debe y puede hacer el Seminario para que la formación no se interrumpa o incluso más aún, qué actitudes debe madurar en el individuo durante su estancia en el Seminario como comunidad formativa para que pueda integrarse sin rupturas en la fraternidad sacramental del presbiterio diocesano con su obispo a la cabeza?. Releamos juntos de nuevo el número 71 de PDV a fin de enmarcar el tema en sus justas coordenadas:

La formación permanente de los sacerdotes, tanto diocesanos como religiosos, es la continuación natural y absolutamente necesaria de aquel proceso de estructuración de la personalidad presbiteral iniciado en el seminario o en la casa religiosa, mediante el proceso formativo para la ordenación.

Es de mucha importancia darse cuenta y respetar la intrínseca relación que hay entre la formación que precede a la Ordenación y la que le sigue. En efecto, si hubiese una discontinuidad o incluso una deformación entre estas dos fases formativas, se seguirían inmediatamente consecuencias graves para la actividad pastoral y para la comunión fraterna entre los presbiteros, particularmente entre los de diferente edad. La formación permanente no es una repetición de la recibida en el Seminario, y que ahora es sometida a revisión o ampliada con nuevas sugerencias prácticas, sino que se desarrolla con contenidos y sobre todo a través de métodos relativamente nuevos, como un hecho vital unitario que, en su progreso -teniendo sus raíces en la formación del seminario - requiere adaptaciones, actualizaciones y modificaciones, pero sin rupturas ni solución de continuidad,

Y viceversa, desde el seminario mayor es preciso preparar la futura formación permanente, y fomentar el ánimo y el deseo de los futuros presbíteros en relación con ella, demostrando su necesidad, ventajas y espíritu, y asegurando las condiciones de su realización.

Precisamente porque la formación permanente es una continuación de la del Seminario, su finalidad no puede ser una mera actitud, que podría ser 'profesional', conseguida mediante el aprendizaje de algunas técnicas pastorales nuevas. Debe ser más bien el mantener vivo un proceso general e integral de continua maduración, 
mediante la profundización, tanto de los diversos aspectos de la formación -humana, espiritual, intelectual y pastoral- , como de su específica orientación vital e íntima, a partir de la caridad pastoral y en relación con ella.

\subsection{Otros documentos}

Pocos años más tarde, otra exhortación apostólica, la Vita Consecrata (1996), fruto del Sínodo sobre la Vida Consagrada, señalaba que el objetivo central del proceso formativo es la preparación de la persona para la consagración total de sí misma a Dios en el seguimiento de Cristo, al servicio de la misión (n.65). Y al comenzar el tratado de la formación permanente escribe:

La formación permanente, tanto para los Institutos de vida apostólica como para los de vida contemplativa, es una exigencia intrínseca de la consagración religiosa. El proceso formativo, como se ha dicho, no se reduce a la fase inicial, puesto que, por la limitación humana, la persona consagrada no podrá jamás suponer que ha completado la gestación del aquel hombre nuevo que experimenta dentro de sí, ni de poseer en cada circunstancia de la vida los mismos sentimientos de Cristo. La formación inicial, por tanto, debe engarzarse con la formación permanente, creando en el sujeto la disponibilidad para dejarse formar en cada uno de los días de su vida.

Es muy importante, por tanto, que cada Instituto incluya, como parte de la ratio institutionis, la definición de un proyecto de formación permanente lo más preciso y sistemático posible, cuyo objetivo primario sea el de acompañar a cada persona consagrada con un programa que abarque toda su existencia. Ninguno puede estar exento de aplicarse al propio crecimiento humano y religioso; como nadie puede tampoco presumir de sí mismo y llevar su vida con autosuficiencia. Ninguna fase de la vida puede ser considerada tan segura y fervorosa como para excluir toda oportunidad de ser asistida y poder de este modo tener mayores garantías de perseverancia en la fidelidad, ni existe edad alguna en la que se pueda dar por concluida la completa madurez de la persona (n.69).

La V Conferencia del Episcopado Latinoamericano y del Caribe, celebrada en la primavera de 2007, refiriéndose al proceso de formación de los discípulos misioneros, en su Documento final afirma:

El itinerario formativo del seguidor de Jesús hunde sus raíces en la naturaleza de la persona y en la invitación personal de Jesucristo, que llama a los suyos por su nombre, y estos le siguen porque conocen su voz. El Señor despertaba las aspiraciones profundas de sus discípulos y los atraía a sí, llenos de asombro. El seguimiento 
es fruto de una fascinación que responde al deseo de una realización humana, al deseo de vida plena. El discípulo es alguien apasionado por Cristo, a quien reconoce como el Maestro que lo conduce y acompaña (n.277).

\subsection{Definición de seminario y de formación permanente}

Es otro punto de partida para evitar posibles confusiones posteriores. Admitiendo que el seminario mayor es el lugar optimo de formación (PDV, 60 ), que es como la casa propia para la formación de los candidatos al sacerdocio, no se debe olvidar que el seminario es sobre todo una comunidad educativa en camino...la identidad profunda del seminario es la de ser, a su manera, una continuación en la Iglesia, de la única comunidad apostólica formada en torno a Jesús con la escucha de la Palabra, en camino hacia la experiencia de la Pascua (PDV, 61).

El seminario tiene una identidad propia, pero su finalidad última está fuera del mismo. El joven que ingresa en el seminario no lo hace para ser siempre seminarista; la finalidad del seminario es formar pastores (OT, 4). Por lo tanto, todos los ámbitos formativos, las dimensiones y los programas deben estar encaminados a este objetivo.

Es de gran riqueza la expresión comunidad educativa en camino; pero un camino en cuyo recorrido la ordenación sacerdotal es el final de una etapa, pero no es la meta final de la formación. En este sentido, la formación permanente la definimos también como un proceso vital, dinámico. Es un asunto:

De vida (no almacén de información) que comienza, se realiza y termina con la vida;

Para la vida, es decir, para responder eficazmente a los actos que la vida presenta y desafían nuestra imaginación creadora;

En la vida, no al margen de la trama de los acontecimientos, sino en el corazón de ellos; en la aventura diaria de la humanidad en la que estamos y nos rodea.

La vida y el ministerio tienen que contemplarla como una realidad salpicada de innumerables ocasiones formativas que mantienen jóvenes y capaces de mejorar continuamente, sostiene alta la tensión saludable del crecimiento y la capacidad para apreciar las novedades y la belleza de la vida6. Los autores, sobre todo americanos, sintetizan el proceso dinámico de la formación permanente en tres etapas: olvidar, aprender o cambiar e integrar:

a. Olvidar que no es sinónimo de borrar o anular los conocimientos,

6 Cencini, A., La formación permanente. Madrid, 2002, 40-43. 
sino tomar distancia del pasado sin indiferencia ni desprecio; pero tampoco convertir el presente en un jardín de añoranzas;

b. Aprender, como el momento más preciso para garantizar el proceso de la formación y de la formación permanente. No basta olvidar lo que estorba, hay que aprender lo que falta. Está bien mirar el trayecto recorrido para crear esperanza, pero hay que mirar lo que resta para concluir la etapa a fin de ofrecernos a nosotros mismos un futuro, medir las fuerzas y calcular los tiempos.

c. Y, sobre todo, integrar. Vivir en actitud de apertura a todas las interpelaciones que sentimos a nuestro alrededor. Hay que estar siempre preparados para reformar la primera formación. Con la continua preocupación por renovarla 7 .

En definitiva: que el asombro vocacional que nació con la opción y se alimentó en el seminario, no se apague con el ejercicio del ministerio, sino que sea como la luz que no mengua al repartirse.

\subsection{Tema reiterativo en los años postconciliares}

Ya la instrucción Inter Ea de la Congregación del Clero en 1969 hacía referencia a un curso de pastoral después de la ordenación sacerdotal que comprenda contenidos bien determinados y un explícito acompañamiento además de los cursos... y todo ello coordinado con el proyecto del Seminario 8 .

Preparando el Sínodo sobre la formación sacerdotal, en los Lineamenta encontramos referencias concretas: La formación permanente no termina con la ordenación sacerdotal. Debe continuarse a lo largo de toda la vida del sacerdote... la formación es un proceso dinámico. Esta progresión sigue una serie de etapas, que presentan dificultades y recursos propios (n.32).

En el Instrumentum Laboris del mismo Sínodo se afirma claramente que la formación permanente es la prolongación natural de aquel proceso de estructuración de la personalidad presbiteral que se inicia en el camino formativo con vistas a la ordenación. Se extiende a toda la vida y se propone profundizar los aspectos humano, espiritual, doctrinal y pastoral (n.54). Se trata de una formulación que va a pasar prácticamente íntegra en sus términos a PDV y a las Ratios posteriores, como enseguida se verá.

Juan Pablo II en su discurso del 15 de febrero de 1990 a los miembros de la secretaría del Sínodo les decía que el próximo Sínodo tratará de la formación

7 Cfr. Guerrero-Valderrábanos. La formación permanente, una llamada apremiante en Testimonio, 95.

8 Cfr. el texto integro en Ecclesia,30 (1970) 237-241. 
que hay que impartir a los presbíteros al principio de la manifestación de su llamada, durante el tiempo de preparación para la ordenación, y en el periodo de vida sacerdotal9.

Ya en el mes de diciembre del año anterior había recordado que justamente para ser plenamente aceptada (la vocación) y producir todos sus frutos, esta llamada requiere una formación que permita el desarrollo de todo lo que ha sido sembrado por la gracia ${ }^{10}$. En otro discurso, unos meses antes, se refería a la formación que debe darse a los aspirantes al sacerdocio para ser testigos del reino espiritual mediante la renuncia a perseguir riquezas materiales ${ }^{11}$.

Al finalizar las tareas del Sínodo en otoño de 1990, los padres sinodales en el Mensaje al Pueblo de Dios y dirigiéndose a los seminaristas, les decían: Tened siempre presente en vuestro espíritu que la formación sacerdotal es un camino que dura toda la vida12.

Toda esta doctrina será formulada en el documento más orientador, fruto de los trabajos del Sínodo: la exhortación apostólica Pastores Dabo Vobis del 25 de marzo de 1992: la finalidad pastoral asegura a la formación humana, espiritual e intelectual algunos contenidos y características concretas, a la vez que unifica y determina toda la formación de los futuros pastores (n.57). El proyecto educativo del seminario se encarga de una verdadera y propia iniciación a la sensibilidad del Pastor, a asumir de manera consciente y madura sus responsabilidades, el hábito interior de valorar los problemas y establecer prioridades y medios de solución, fundados siempre en claras motivaciones de fe y según las exigencias de la pastoral misma (n.58).

Este texto que se refiere directamente a la formación pastoral hemos de leerlo a la luz del número 71 de la misma exhortación: La formación permanente de los sacerdotes, tanto diocesanos como religiosos, es la continuación necesaria de aquel proceso de estructuración de la personalidad presbiteral iniciado y desarrollado en Seminario o en la Casa Religiosa, mediante el proceso formativo para la Ordenación $n^{13}$.

Las Ratios nacionales son sensibles al tema de la relación que debe darse entre la formación en el Seminario y la formación permanente. Veamos algunos ejemplos de una y otra orilla del océano:

9 Texto íntegro en L'Osservatore Romano Ed. en lengua española, 10 (11-3-1990) 9.

10 En el Ángelus de del 3 de Diciembre de 1989.

11 En L'Obs. R. 28 (15-07-1990) 1.

12 Apartado IV. En L'Obs. R. 44 (2-10-1990) 12.

13 Texto tomado al pie de la letra de los Lineamenta. Cfr. OT, 22: la formación sacerdotal debe continuarse y perfeccionarse incluso una vez terminado el ciclo de estudios en los Seminarios. 
La edición italiana subraya que no se trata de una simple repetición e indicando que entre una y otra no deben producirse rupturas sino que debe existir continuidad ${ }^{14}$.

El documento La formación para el Sacerdocio Ministerial de la Conferencia Episcopal Argentina del 1 de mayo de 1994, en su apartado IV dedicado a la Formación Permanente, hace suyo el texto de PDV 71 en cuanto al proceso de estructuración de la personalidad iniciado y desarrollado en el seminario. Seguidamente se expresa en estos términos: Es de mucha importancia darse cuenta y respetar la intrínseca relación que hay entre la formación que precede a la Ordenación y la que le sigue. Por eso, desde el seminario mayor es preciso preparar la futura formación permanente, y fomentar el ánimo y el deseo de los futuros presbíteros en relación con ella, demostrando su necesidad, ventajas y espíritu, y asegurando las condiciones de su realización ${ }^{15}$.

La Comisión Episcopal de Seminarios y Vocaciones de la Conferencia Episcopal de México en su publicación titulada Documentos para la Formación sacerdotal, dedica el capítulo VII a la formación permanente y, entre otras cosas, escribe:

198.- Sin que se pretenda legislar sobre la formación permanente, las presentes Normas señalan la continuidad de la formación integral del que pasa del Seminario a la vida ministerial;

199.- La formación permanente de los sacerdotes es la continuación natural y absolutamente necesaria de aquel proceso de estructuración de la personalidad presbiteral iniciado y desarrollado en el Seminario mayor...

200.- Prepárese a los alumnos, desde el Seminario mayor, para la formación permanente, que ha de desarrollarse como proceso vivo, general e integral de continua maduración. Para este fin, hágase conscientes a los alumnos de la necesidad y de los fundamentos de dicha formación permanente, y foméntese el ánimo y el deseo de los futuros presbiteros para asumirla. Citando PDV 76, añade: $\mathrm{Ha}$ de rechazarse como absolutamente falsa y peligrosa la idea de que la formación presbiteral concluye con la estancia en el seminario.

203.- Implemente la Comisión del Clero un Plan Nacional de Formación Permanente, para el servicio de las diócesis.

204.- Plan especial de formación integral...en coordinación con los formadores del Seminario y la comisión diocesana del clero...para

14 Cfr. Orientamenti e norme.

15 Cfr. Plan para los Seminarios de la República Argentina, nn.291-292. 
todas las edades ${ }^{16}$.

En la misma línea se expresa la Conferencia Episcopal Ecuatoriana: El Seminario mayor, ambiente natural de la formación inicial, prepara la formación permanente, fomentando el ánimo, el deseo y la conciencia de su necesidad, de su espíritu y de sus ventajas y asegurando las condiciones de su realización, para mantener vivo el proceso general e integral de continua maduración en cada aspecto de la formación ${ }^{17}$.

El Plan de Formación Sacerdotal para los Seminarios mayores de España plantea directamente la tercera etapa en el que el ejercicio de la práctica pastoral, juntamente con el estudio de las materias teológicas y técnicas más directamente relacionadas con la acción pastoral, pasa a constituir el elemento principal de formación (n.210).

En todo caso, su incorporación progresiva al presbiterio diocesano y su participación creciente en las tareas pastorales, hasta llegar a una dedicación exclusiva, requiere un periodo de transición prolongado y bien programado, que debe cuidarse con sumo esmero (n.212).

Señala finalmente que siendo esta etapa pastoral parte integrante de la formación del futuro pastor, corresponde a los formadores del seminario tomar parte en su planificación, desarrollo y evaluación. Dadas, por otro lado, las implicaciones de esta etapa en la organización y en la acción pastoral de la diócesis, resultará necesario que la vicaría general o la de pastoral, en conexión con los distintos organismos diocesanos, asuman también su responsabilidad en la planificación y en la evaluación de esta fase, muy especialmente a partir de la ordenación diaconal (n.22) ${ }^{18}$.

Finalmente, el Documento de Aparecida de mayo de 2007 dice que es oportuno señalar la complementariedad entra la formación iniciada en el Seminario y el proceso formativo, que abarca las diversas etapas de la vida del presbítero. Hay que despertar la conciencia de que la formación sólo termina con la muerte...Al respecto, se requieren proyectos diocesanos bien articulados y constantemente evaluados (n.326).

En una primera síntesis de los textos presentados podemos subrayar que lo importante es que haya una solución de continuidad entre la llamada formación inicial y la permanente para poder hablar de una Formación Continuada.

16 Cfr.ed. de 1996.

17 Normas de aplicación en el Ecuador de la R.F.I.S y Reglamento del Seminario. 5 de agosto de 1995, n.320.

18 La formación para el Ministerio Presbiteral. Madrid, 30 de mayo de 1996. 
La inicial debe dejar el camino preparado para la permanente y ésta debe volver la mirada a la inicial. No se trata de repeticiones ni de ampliaciones, sino de perfeccionamiento y de profundización como hecho vital, como proceso continuo y global que sirva para siempre y para todos.

Lo que si está claro -dice un comentarista del tema- es que después del Concilio aparece una doble exigencia; la responsabilidad de la comunidad educativa del seminario y la responsabilidad de las Iglesias particulares para una pastoral sacerdotal que acompañe toda la vida del ministerio de todos los pastores ${ }^{19}$.

\section{ALGUNOS INTERROGANTES}

\section{1. ¿Dónde colocar el límite entre la formación inicial y la formación permanente?}

Parece claro que no se puede colocar dicho límite al concluir el ciclo seminarístico o con la ordenación sacerdotal. De hecho, el mismo decreto conciliar OT habla de un perfeccionamiento tanto de la vida como de la actividad apostólica

Es cierto que para muchos formadores y alumnos la fase educativa es considerada como un primer tiempo de la formación inicial que sólo en un segundo tiempo de la misma formación inicial conducirá al joven sacerdote a entrar en la formación permanente.

Colocar el final de dicha formación después de cuatro o cinco de ejercicio del ministerio ayuda a valorar las primeras experiencias de vida y de ministerio como partes integrantes de la formación inicial que el Seminario no pudo madurar. Sin negar el papel del seminario, pero vale como medio para que el candidato supere la ilusión/tentación de que el programa de estudios y las experiencias pastorales realizadas durante los años del mismo completan su formación y ya no tiene necesidad de más.

PO 22, en la brevedad de sus términos, da a entender que es necesario algo apropiado como señalará después la R.F.I.S. de 1970, superando en parte la Instrucción Inter Ea de la Congregación del Clero de 1969, pues en aquella se hace referencia a un bienio pastoral posterior a la ordenación con unos contenidos y actividades apropiadas en perfecta relación con el plan formativo del Seminario20.

19 Melguizo, G., Integralidad y continuidad de la formación inicial y permanente del Ministerio sagrado en Medellín, vol XXVIII, n.109 (2002) 19.

20 Cfr. Coletti, ED., Formazione permanente del clero: come, a quali condizioni e per quale scopo en Seminarium, 3 (2005) 701 ss. 
Ni PO ni OT tratan directamente el tema y por lo tanto la reflexión actual debe hacerse continuando el análisis de las experiencias posteriormente realizadas en el arco de estos casi 45 años y teniendo como foco de luz permanente lo dicho en el Sínodo sobre la Formación sacerdotal en el mundo actual y que sigue iluminando el camino formativo ya casi veinte años con sus reflexiones en el aula y con la posterior exhortación PDV del papa Juan Pablo II.

\section{2. ¿Pueden los seminarios actuales responder a las exigencias forma- tivas que se les plantean y preparar el ambiente de una formación permanente tal como es entendida en la actualidad?}

Para responder a esta pregunta se ha de partir del hecho de que no existe un modelo único de centro formativo. Coexisten diversos modelos $\mathrm{y}$, por tanto, diversidad de proyectos aunque todos se propongan la misma finalidad: formar pastores. Pero la diferencia institucional no evita el que se constaten situaciones, riesgos y dificultades comunes.

Jean Busquets, hace ya quince años, ofreció su reflexión al respecto y la mayoría de sus apreciaciones siguen teniendo actualidad. El autor afirma que no es fácil compaginar la dedicación seria y constante al estudio con la misma seriedad en la preparación y en el ejercicio de la pastoral; la necesidad de formadores suficientes y dedicados únicamente a la formación de los candidatos; la influencia de las comunidades de origen a las que ya se refería PDV en sus aspectos positivos y en que no sean una alternativa a la institución (n.68); la falta de interés en algunos sectores del clero o cierta actitud de prejuicio sobre los jóvenes aspirantes al sacerdocio por parte de otros; la aportación de las asociaciones sacerdotales y el que la formación permanente no puede suplir las carencias de un seminario de vía rápida21.

El mismo autor ofrece posibilidades para la etapa diaconal o pastoral en los apartados dedicados a la espiritualidad, la pastoral y el estudio, así como algunas sugerencias prácticas, concluyendo que el seminario y la formación permanente constituyen dos etapas de un único proyecto formativo; que el seminario debería conectar con la nueva concepción de formación permanente, sin olvidar que el seminario sólo es formativo si no se queda en propósitos para el futuro y consigue iniciar de verdad a un talante de vida: la forma de vida apostólica22.

21 Cfr. Seminario y formación permanente de los sacerdotes en Simposio, Edice,1993, 204-233.

22 Id, 232. 


\section{DE LA COMUNIDAD FORMATIVA A LA FRATERNIDAD PRESBI- TERAL}

Después de todas las consideraciones anteriores, entendemos que no se trata de fijar límites, sino de trabajar en la elaboración y puesta en práctica de un proyecto de formación integral que comenzando en el seminario y continuando toda la vida, tenga como objetivo el de acompañar al sacerdote y a toda persona consagrada a conformar su existencia y su ministerio con Jesucristo, cabeza y pastor de la Iglesia.

El seminario, con sus valores y sus límites, debe ser un medio eficaz para que el aspirante ya en los últimos años de formación seminarística dé el salto desde la comunidad educativa en camino (PDV, 60) a ser presbítero como una representación sacramental de Jesucristo cabeza y pastor (PDV, 15).

Dicho con otras palabras, el seminario debe ser el cauce formativo para que el candidato entienda y acepte que ser llamado al sacerdocio, es ser llamado a formar parte de la familia presbiteral. Así como la Iglesia no tiene un fin en sí misma, sino que ha sido fundada para evangelizar, el seminario ha de tener como objetivo sacar hombres que sean luz del mundo, sal de la tierra y gloria de Cristo ${ }^{23}$. Con expresión inicial del Papa en la PDV: dar a la Iglesia pastores según el corazón de Dios.

En otro momento me atreví a ofrecer algunas conversiones continuas a las que debía servir la formación permanente ${ }^{24}$; ahora me aventuro a formular algunos de los principios y objetivos que pudieran y debieran tenerse en cuenta en un proyecto formativo en el que el Seminario sirviera para apoyar la recepción primero y más tarde la realización gozosa de una formación continuada hasta el final de la vida.

Como ideas generales avanzo que en dicho proyecto se deben contemplar lo medios necesarios para que ya desde el seminario

a. se vaya estructurando la personalidad del pastor dándole los elementos para su unidad y equilibrio;

b. ayudarle para que vaya asumiendo, especialmente en los últimos cursos, que el eje orientador de su próxima vida ministerial ha de ser la caridad pastoral (PDV, 60) entendida como la actitud que conduce al pastor a dar la vida por los fieles, la donación total de sí a la Iglesia por amistad con el Esposo (PDV, 32);

23 San Juan de Ávila. Obras Completas, II, p.494.

24 Rubio Parrado, L., Formación Permanente en Seminarios, 189-190 (JulioDiciembre 2008) 123-167. 
c. potenciar la integración de los valores y actividades de la vida, que quiere decir seguir viviendo en actitud de búsqueda permanente para estar siempre abierto al aprendizaje, de tal manera que entienda claramente que con la conclusión de los estudios del programa académico y con la ordenación, nada ha terminado en el campo formativo,

d. prepararse para saber conjugar el discernimiento de las opciones pastorales concretas con la interiorización de estas para que el primero sea acertado. Se trata, como es claro advertir, de una prueba de madurez.

El Plan de Formación Sacerdotal para los Seminarios de España sintetiza esta idea al escribir que los seminaristas van asimilando y profundizando progresivamente en el Seminario los diversos aspectos necesarios para la vida y el ministerio presbitera/25. Pero todo ello, por una razón fundamental pedagógica debe verterse en una programación eficaz que permita más tarde una educación continua, personal y comunitaria.

Se trata de programar un período de transición prolongado que garantice la incorporación progresiva del candidato al presbiterio diocesano y su participación creciente en las tareas pastorales ${ }^{26}$. Es algo más que el ejercicio de la práctica pastoral durante su estancia en el Seminario, algo más que el estudio de técnicas pastorales y en ningún caso se debe confundir con las llamadas interrupciones que tienen sus propias motivaciones y sus objetivos a satisfacer.

Señalemos finalmente o recordemos que en esta etapa formativa no pueden estar ausentes los miembros del equipo formativo del seminario, todos los educadores ya que el seminario, como comunidad formativa, ha de vivir siempre en continuo diálogo mutuo entre los que se forman y los formadores $^{27}$.

Pasemos ahora a los principios y objetivos que deben conformar el proyecto:

\subsection{Iniciación a la sensibilidad del pastor (PDV, 58)}

Ya hemos apuntado más arriba que las dimensiones formativas a cuidar en el seminario no pueden separarse. La misma exhortación PDV lo repite insistentemente al referirse a cada una de ellas. Por ello recordamos que todo el

\footnotetext{
25 Edición de 1996,n.150.

26 Id, n. 212.

27 OT, 5 y RFIS. 21.
} 
tiempo, todo el espacio, todos los formadores deben estar al servicio de todas ellas en un solo y mismo espíritu, y cuidando esmeradamente las relaciones mutuas y los elementos integradores:

- La formación espiritual ha de estar estrechamente unida a la doctrinal y pastoral (OT, 8);

- Que los alumnos mediante las disciplinas filosóficas lleguen a un conocimiento sólido y coherente del hombre, del mundo y de Dios (OT, 15);

- Para que pueda ser pastoralmente eficaz, la formación intelectual debe integrarse en un camino espiritual marcado por la experiencia personal de Dios (PDV, 56);

. OT, 11 coloca la formación humana en el capítulo de la formación espiritual;

- La RFIS nos dice que La formación espiritual debe abarcar el hombre entero (n.15);

- Finalmente PDV es muy clara al afirmar: sin una adecuada formación humana toda la formación estaría privada de su fundamento necesario (n.43).

Para el apartado al que nos estamos refiriendo, los diversos documentos son extraordinariamente claros:

- La preocupación pastoral debe informar por entero la formación de los alumnos (OT, 18) ;

- El espíritu pastoral debe informar enteramente la formación sacerdotal' (RFIS, 94).

El futuro pastor necesita una formación integra, global y unitaria de su personalidad para que su ministerio sea completo y equilibrado, tanto en los aspectos humanos como en los espirituales y pastorales. Solo así serán maduras sus opciones pastorales y su integración en proyectos comunitarios y relaciones personales.

El tema no es solamente de adquisición de saberes, sino de la formación de una sensibilidad marcada por las cualidades del pastor que no va buscando el propio interés en sus relaciones con los fieles, sino en la entrega generosa a la que se refiere San Pedro en la primera de sus cartas: Apacentad el rebaño que os ha sido confiado...no por los beneficios que pueda reportaros, sino con ánimo generoso (1 Pe. 5, 3).

Este talante no se improvisa. El seminario debe ir limando, desde todos los ángulos posibles, intereses personales o familiares, ambiciones escondidas, realizaciones deseadas, prestigios buscados por el ministerio, y todo ello exige dedicación a la persona concreta para que se vayan dibujando en el 
candidato los rasgos del Pastor.

El pensamiento nos lo transmite con claridad Juan Pablo II cuando en su exhortación sobre la formación sacerdotal escribe:

La finalidad pastoral asegura a la formación humana, espiritual e intelectual algunos contenidos y características concretas, a la vez que unifica y determina toda la formación de los futuros sacerdotes. El proyecto educativo del seminario se encarga de una verdadera y propia iniciación a la sensibilidad del pastor, asumir de manera consciente y madura sus responsabilidades, al hábito interior de valorar los problemas y establecer las prioridades, y los medios de solución, fundados siempre en claras motivaciones de fe y según las exigencias teológicas de la pastoral misma (PDV, 57 y 58)28.

Pienso que la comprobación de esa sensibilidad de pastor puede ser uno de los criterios objetivos para la admisión de un candidato a las sagradas órdenes del diaconado y más aún al presbiterado.

\subsection{Preparar para realizar una pastoral comunitaria (PDV, 59)}

El presbiterado es un carisma de totalidad como respuesta a la llamada vocacional. Y el ministerio es una llamada que se realiza en un presbiterio que no es la mera yuxtaposición de presbíteros singulares, sino una realidad sacramental que, en torno al Obispo, ha recibido el ministerio de la comunidad y por ello preside la Eucaristía y garantiza la apostolicidad de la Iglesia29.

PO nos dice por una parte que ningún presbítero puede cumplir cabalmente su misión aislada o individualmente (n.7) y añade en el párrafo siguiente que cada uno de ellos está unido con los demás miembros de su presbiterio con los lazos especiales de amor apostólico, ministerio y fraternidad... cada uno está unido con sus hermanos por lazos de amor, oración y todo tipo de colaboración (n.8).

PDV recuerda que el orden se confiere a cada uno en singular, pero quedan insertos en la comunión del presbiterio unido al obispo (n.74; cfr. PO, 7; LG,28) .

La cultura actual tiende a separar fuertemente el ser, el hacer y el vivir al tiempo que tiende a fragmentar los distintos aspectos de la personalidad. Frente a esta situación, PDV nos indica que la formación pastoral está orien-

28 Cfr. Melguizo. Integralidad...oc, p.13-14; Andrades Ledo, F., La formación pastoral en Seminarios, 189-190 (julio-diciembre, 2008) 93-94.

29 Bueno de la Fuente, E., Iglesia local en Diccionario del Sacerdocio. Bac, Madrid, 2005, 323-333. 
tada a preparar a los candidatos de una manera específica para comunicar la caridad de Cristo, Buen Pastor. El estudio y la actividad pastoral se apoyan en una fuente interior, que la formación deberá custodiar y valorizar: se trata de la comunión cada vez más profunda con la caridad pastoral de Jesús... se trata de una formación destinada no solo a asegurar una competencia pastoral científica y una preparación práctica, sino también, y sobre todo, a garantizar el crecimiento de un modo de estar en comunión con los mismos sentimientos de Cristo, Buen Pastor: tener entre vosotros los mismos sentimientos de Cristo (Fil 2, 5) (PDV, 57).

Tema importante en todo proyecto formativo del seminario. Frente a ciertas tendencias individualistas en los sacerdotes, se tratará de preparar al seminarista para insertarse en el proyecto diocesano. Para ello es importante conocerlo, prepararse para una participación activa en su realización conociendo sus destinatarios, induciendo a un conocimiento sincero y empático de las situaciones socio-culturales en las que estos se encuentran y aprendiendo a discernir con criterio evangélico las actuaciones a realizar.

Una concreción práctica será la de preparar al seminarista para desarrollar un trabajo en equipo. Aprender a planificar, a contrastar y a rectificar .En la vida y trabajo de equipo los problemas se relativizan, el diálogo enriquece, se comparten las tareas y en la medida en que el trabajo se hace también vida, se afianza la vocación al sacerdocio como más tarde se consolida la vocación en el sacerdocio.

Sería empobrecedor que por la estructura del seminario y por las experiencias pastorales realizadas desde el mismo no aprendiera el candidato a valorar otros dones y carismas como el de los laicos y el de la vida consagrada. En definitiva se trataría de que la estructura formativa del seminario se sitúe en el ámbito de la Iglesia comunión. Lo que PDV dice de la formación permanente vale para toda etapa formativa: La participación de vida entre el presbitero y la comunidad supone una aportación fundamental a la formación permanente...

La experiencia cristiana de las personas sencillas y humildes, los impulsos espirituales de las personas enamoradas de Dios, la valiente aplicación de la fe a la vida por parte de los cristianos comprometidos en las diversas responsabilidades sociales y civiles, son acogidas por el presbítero -también deben serlo por el seminarista- $y$ a la vez que las ilumina con su servicio sacerdotal, encuentra en ellas un precioso alimento espiritual (PDV, 79). En el caso del seminarista es una fuente de energía en su vida comunidad educativa en camino, porque el contacto con todas estas personas y realidades estimulan para seguir caminando y hacerlo junto a otros que caminan en la misma dirección.

3.3. Para incorporarse a una Iglesia particular y desarrollar el sentido de 


\section{pertenencia a la misma, pero con carácter universal}

El seminarista, por la ordenación que un día recibirá, está llamado a madurar la conciencia de ser de una Iglesia particular en la que está incardinado, o sea, incorporado con un vínculo a la vez jurídico, espiritual y pastoral (PDV, 74).

Esta conciencia debe ayudarle, ya desde el Seminario a:

a. desarrollar el amor especial a su propia diócesis;

b. madurar en la conciencia de comunión que existe entre las diversas Iglesias particulares;

c. Crecer en y con el propio presbiterio unido al Obispo;

d. Enriquecerse con los diversos estilos de espiritualidad existentes en la diócesis;

e. Afrontar positivamente la soledad sacerdotal...

Este amor a la propia Iglesia le viene del sentido de pertenencia que desarrolla en la persona del seminarista o del sacerdote la capacidad de amar a la comunidad presbiteral, de sentirla como propia y verdadera familia, de acoger a sus hermanos con toda su carga de limitaciones y debilidades, de dones y de pobrezas, decidiendo ser o desear ser un presbiterio.

La exhortación apostólica PDV lo dirá con fuerza:

Es necesario considerar como valor espiritual del presbitero su pertenencia y su dedicación a la Iglesia particular, lo cual no está motivado solamente por razones organizativas y disciplinares, al contrario, la relación con el Obispo en el único presbiterio, la coparticipación en su preocupación eclesial, la dedicación al cuidado evangélico del Pueblo de Dios en las condiciones concretas históricas y ambientales de la Iglesia particular, son elementos de los que no se puede prescindir al dibujar la configuración propia del sacerdote y de su vida espiritual. En este sentido la 'incardinación' no se agota en un vínculo puramente jurídico, sino que comporta también una serie de actitudes y opciones espirituales y pastorales, que contribuyan a dar una fisonomía específica a la figura vocacional del presbiterio (n.31).

De aquí se deriva que la primera comunidad natural para el presbítero es la comunidad de los sacerdotes ordenados. En cuanto al concepto de pertenencia es oportuno recordar como lo entiende Cencini:

A. Relación humana consistente en amistad sincera entre sacerdotes, capacidad de vivir juntos, de trabajar unidos, de rezar en común; crecer sabiéndose responsables los unos de los otros, convirtiéndo- 
se mutuamente a través de la corrección fraterna.

B. Conciencia de una experiencia viva de espiritualidad como acontecimiento comunitario. No tendría sentido una espiritualidad del sacerdote vivida como propiedad privada; tampoco una espiritualidad del clero secular que tenga que ser tonificada o colonizada por instancias ajenas a las diócesis.

C. El compartir práctico y operativo: compartiendo el plan diocesano con la mente y el corazón, superando el endémico individualismo clerical. Dedicación a la Iglesia que nace de un amor esponsal-virginal, sin barras ni condiciones, para siempre y con todas las fuerzas.

El sentido de pertenencia del sacerdote a la comunidad presbiteral, o el sentido de diocesanidad, suele ser un signo evidente de la identidad sacerdotal 30 .

\subsection{Sentido de la comunión eclesial, orgánica y universal}

Me parece de especial interés recordar aquí lo que el hoy cardenal Vanhoye decía ya en el Simposio sobre Espiritualidad del presbítero diocesano secular al final de los años ochenta:

La espiritualidad sacerdotal debe estar profundamente marcada por el sentido de 'comunión eclesial'. De hecho, el don divino concedido por medio del sacerdote es don de comunión en el amor. El sacerdote es sacramento de la mediación de Cristo, mediación que sólo pretende introducir a los hombres en la comunión divina, que los une con Dios y los vincula entre sí. La mediación de Cristo no solamente relaciona con Dios al creyente individual. También une a todos los creyentes en un único Pueblo de Dios. Por consiguiente, el sacerdocio ministerial, signo e instrumento de Cristo mediador, no solamente ofrece al creyente la ocasión de unir la propia existencia a la de Cristo; es también función suya estructurar el cuerpo de Cristo, creando una unidad, una comunión. Según Efesios 4, 12, Cristo otorga a sus ministros 'para capacitar a los santos, es decir, a los cristianos, en la tarea de servicio, para la construcción del cuerpo de Cristo, hasta que todos alcancemos la unidad de la fe'. Nunca como ahora - pues el Concilio ha definido la Iglesia como una comunión- es necesario que el sacerdote esté imbuido de un fuerte dinamismo espiritual de comunión.

El sacramento del orden expresa claramente que se trata de una 'comunión orgánica'. La Iglesia no es una masa informe. Es cons-

30 Cfr. Trujillo, L., Relaciones propias del presbitero y su espiritualidad en Espiritualidad sacerdotal. Congreso. Edice, Madrid,1989,168-171. 
trucción estructurada; es casa de Dios; es cuerpo de Cristo. El sacerdote debe ser consciente de que no posee un sacerdocio individual, sino que forma parte de 'un orden sacramental', a través del cual Cristo reúne orgánicamente en su cuerpo a todos los hijos de Dios, de otra manera dispersos (Cfr. Jn 11,52); Rom 12, 5). La unión de todo el presbiterio en torno al Obispo es el fruto directo de la ordenación sacramental...

Otra consecuencia de todo esto es que la espiritualidad sacerdotal debe tener 'apertura universal'. Porque los sacerdotes no son mediadores independientes, sino representante del único Mediador, que no pueden formar comunidades separadas, aisladas; su misión consiste en vincular a sus fieles con la totalidad del Pueblo de Dios. El sacerdote es signo e instrumento de comunión en la Iglesia local; pero a causa de la unidad del sacerdocio cristiano, el sacerdote es, al mismo tiempo, signo e instrumento de comunión de la Iglesia particular con toda la Iglesia universaß ${ }^{1}$.

Como un apartado de singular importancia dentro de la comunión, añadimos la formación a la fraternidad y a la comunión a la que hace años aludía expresamente el entonces Prefecto de la Congregación para la Educación Católica, el cardenal Pio Laghi. El denominaba,

La sensibilidad de comunión en la que se debe formar a los futuros sacerdotes: La aptitud para la comunión fraterna y la capacidad de cultivar verdaderas y profundas amistades parecen dimensiones no suficientemente cultivadas todavía en los candidatos al presbiterado. Y sin embargo, las condiciones en que ejercitarán el ministerio, requieren, hoy más que nunca, estas cualidades.

Es necesario, en otras palabras, que los sacerdotes estén en disposición de vivir su propia afectividad, entendida en el sentido de capacidad de amar bien y de aceptar serenamente la propia necesidad de ser amados en el modo justo. Todo esto en un cuadro sereno y liberador de relaciones fuertes de amistad, de fraterna colaboración, de alta sensibilidad y solicitud paterna por las personas amadas, de frecuente y profundo intercambio simbólico interpersonal. Lo cual quiere decir capacidad de dejarse corregir, confianza en el amigo y acogida del otro, ausencia de envidia y de espíritu de agresividad, inclinación a la oblatividad y al servicio gratuito, solicitud y atención a las necesidades de los demás... Pero estas actitudes no se improvisan. Sobre todo, no es posible esperar

31 Vanhoye, A., Sacramentalidad del ministerio en Espiritualidad del clero secular. o.c.,71-85; Véase también Gamarra, S., en o.c. pp.150-204. Los subrayados son nuestros. 
a tenerlas a mano en una situación de crisis o en un momento difícil, si no han sido cultivadas con paciencia y prolongada pedagogía cristiana durante todo el período de la formación.

Para expresarme con un parangón: ¿Qué diríamos de un joven candidato al sacerdocio que mostrase claros síntomas de alergia a la oración? ¿Suscita la misma justificada alarma la alergia a la dimensión comunitaria y fraterna de la vida presbiteral, especialmente si va acompañada de fiel regularidad en el deber y de pronta docilidad a los superiores? En este caso, ¿no subestimamos este elemento de la vida cristiana y sacerdotal? Lo que tiempo atrás era garantizado mayormente por las circunstancias sociales y eclesiales, y podía desarrollarse, por así decir, de modo natural, hoy debe cultivarse con prudente y apasionada inteligencia como se cultiva un arte, como se aprende a tocar un instrumento.

En el caso contrario, los aspectos más negativos y deletéreos de la soledad no tardarán en manifestar su propia fuerza devastadora32.

Aunque parezca reiterativo, recordemos lo que dice PDV:

La conciencia de la Iglesia como comunión ayudará al candidato al sacerdocio a realizar una pastoral comunitaria, en colaboración cordial con los diversos agentes eclesiales. Sacerdotes y Obispo, sacerdotes diocesanos y religiosos, sacerdotes y laicos. Pero esta colaboración supone el conocimiento y la estima de los diversos dones y carismas, de las diversas vocaciones y responsabilidades que el Espíritu ofrece y confía a los miembros del Cuerpo de Cristo; requiere un sentido vivo y preciso de al propia identidad y de la de las demás personas en la Iglesia; exige mutua confianza, paciencia, dulzura, capacidad de comprensión y de espera; se basa sobe todo en una amor a la Iglesia más grande que el amor a sí mismo y a las agrupaciones a las cuales pertenece (n.59).

El amor hecho identificación con la propia diócesis evita, por otra parte, corrimientos hacia otras Iglesias que externamente ofrecen mayores opciones personales, pero menos misioneras.

\subsection{Conocer las distintas formas de asociación sacerdotal, pero edifi- cando siempre la única iglesia y el único presbiterio}

La alusión de PDV a las agrupaciones a las cuales pertenece o puede pertenecer el sacerdote o de las que procede nos obliga a referirnos al tema de la presencia y actuación de las Asociaciones Sacerdotales en los seminarios.

32 Cardenal Pio Laghi, Ámbitos de la formación sacerdotal en La formación del Sacerdote del tercer Milenio. Simposio, Sevilla, 1999. Ed. PPC (Madrid,2000) 359-368. 
El autor ya citado, Busquets, reconoce que pueden ser de una notable ayuda para la espiritualidad del presbítero e incluso para su equilibrio personal. Con frecuencia muchos presbíteros dudan entre caminar solos o ingresar en una asociación. En todo caso, éstas no pueden dispensarse nunca de contribuir a edificar un presbiterio diocesano, único y auténtico, siempre en función de la misión pastoral. Termina dando su clara opinión sobre el tema: En todo caso las 'simpatías' de los seminaristas son legítimas; la pertenencia, clara o solapada, durante los años de formación suele constituir un problema. El se inclina más a la creación de grupos de vida y revisión que puedan continuarse después de la ordenación sacerdotal ${ }^{33}$.

Diez años más tarde, otro autor conocedor del tema y apoyándose en el testimonio de Juan Pablo II afirma que está por hacer el discernimiento de la forma concreta como se articula la existencia, presencia y actuación de los Movimientos y Asociaciones, en la Iglesia local y en la pastoral diocesana.

El mismo papa Juan Pablo II nos dice una palabra iluminadora en su carta apostólica Novo Millenio Ineunte:

Tiene gran importancia para la comunión el deber de promover las diversas realidades de asociación, que tanto en sus modalidades más tradicionales como en las más nuevas de los movimientos eclesiales, siguen dando a la Iglesia universal una viveza que es don de Dios constituyendo una auténtica primavera del Espíritu. Conviene ciertamente que, tanto en la Iglesia universal como en las Iglesias particulares, las asociaciones y movimientos actúen en plana sintonía eclesial y en obediencia a las directrices de los Pastores. Pero es también exigente y perentoria para todos la exhortación del Apóstol: 'No extingáis el Espíritu, no despreciéis las profecías, examinadlo todo y quedaos con lo bueno' (1 Tes, 5,1921) (NMI 46).

Estamos de acuerdo en lo difícil que es, por no calificarlo de imposible, separar espiritualidad, planteamiento pastoral, ideología o doctrina, sentido de pertenencia o adhesión y eclesialidad. Por otra parte, manifiesta el riesgo que puede existir de que las distintas formas de agregación no coincidan en sus objetivos, opciones, criterios, acentos, con los de la diócesis, y se produzcan desajustes ${ }^{34}$.

3.6. Algunos acentos de la espiritualidad a desarrollar en la formación espiritual impartida en el seminario

33 Busquets, J., Seminario y Formación Permanente en La Formación Permanente de los Sacerdotes. Simposio, Madrid, 1993, 203 a 233 el texto completo.

34 Francisco, obispo, La Formación Permanente para la Práctica Pastoral, en Simposio sobre la Formación Pastoral en la vida y ministerio del Sacerdote. Sevilla,23-25 Septiembre 2002, pp 1-32. 
No cabe duda de que la espiritualidad condiciona y marca la actuación pastoral. Por eso es imprescindible que desde el Seminario se potencien tanto en el proyecto formativo como en la vida de cada candidato algunos aspectos de la espiritualidad, dentro siempre de la espiritualidad específica del sacerdote diocesano.

El sentido de la comunión eclesial a que nos hemos referido anteriormente, hemos de completarlo con la profundización para vivir una espiritualidad de comunión.

El Documento de Aparecida nos advierte de las nuevas búsquedas espirituales individualistas (n.156). Ante estas espiritualidades individualistas podemos partir de la espiritualidad derivada del Concilio Vaticano II. Aunque el Concilio no habla de teología espiritual ni de espiritualidad en cuanto tal, sí trata de la vida espiritual de la Iglesia. El Sínodo extraordinario de 1985 pone de relieve que la eclesiología de comunión es la idea central y fundamental de los documentos del Concilio (Cfr. la Relatio finalis). Las cuatro constituciones del Concilio son los cuatro pilares de la espiritualidad conciliar. En efecto, nos dicen los obispos que fundamentalmente se trata de la comunión con Dios, por Jesucristo en el Espíritu Santo. Esta comunión se tiene en la Palabra de Dios y en los sacramentos. El Bautismo es la puerta y el fundamento de la comunión en la Iglesia. La Eucaristía es la fuente y cumbre de toda la vida cristiana. La comunión del Cuerpo eucarístico de Cristo edifica la íntima comunión de todos los fieles en el cuerpo de Cristo, que es la Iglesia. Por ello la eclesiología de comunión no se puede reducir a meras cuestiones organizativas o a cuestiones que se refieren a meras potestades (Id, II C, 1).

Juan Pablo II en la Exhortación Apostólica Novo Millenio Ineunte invita a promover una espiritualidad de comunión como camino espiritual sin el cual de poco servirían los instrumentos externos de la comunión. Por ello presenta la espiritualidad de comunión como el gran desafío para la Iglesia el comienzo del nuevo milenio, siendo fieles al designio de Dios y a las profundas esperanzas del mundo 35 .

\subsubsection{Formar/preparar para una espiritualidad de comunión}

El Papa lo aplica a todos, también donde se educan los ministros del altar. Merece la pena retomar el texto completo del número 43:

Hacer de la Iglesia 'la casa y la escuela de la comunión': éste es el gran desafío que tenemos ante nosotros en el milenio que comien-

35 Cfr. Pinilla, F., Elementos para una espiritualidad de comunión según el número 43 de la Exhortación Apostólica Novo Millenio Ineunte en Revista Católica 1/132 (2001) 271. 
za, si queremos ser fieles a los designios de Dios y responder también a las profundas esperanzas del mundo,

¿Qué significa todo esto en concreto? También aquí la reflexión podría hacerse enseguida operativa, pero sería equivocado dejarse llevar por este primer impulso. Antes de programar iniciativas concretas, 'hace falta promover una espiritualidad de la comunión', proponiéndola como principio educativo en todos los lugares donde se forma al hombre y al cristiano, donde se educan los ministros del altar, las personas consagradas y los agentes pastorales. Donde se construyen las familias y las comunidades. Espiritualidad de la comunión significa ante todo una mirada del corazón sobre todo hacia el misterio de la Trinidad que habita en nosotros, y cuya luz ha de ser reconocida también en el rostro de los hermanos que están a nuestro lado. Espiritualidad de la comunión significa, además, capacidad de sentir al hermano de fe en la unidad profunda del Cuerpo místico y, por tanto, como 'uno que me pertenece', para saber compartir sus alegrías y sus sufrimientos, para intuir sus deseos $y$ atender a sus necesidades, para ofrecerle una verdadera y profunda amistad. Espiritualidad de la comunión es también capacidad de ver todo lo que hay de positivo en el otro, para acogerlo y valorarlo como regalo de Dios: un 'don para mí', además de ser un don para el hermano que lo ha recibido directamente. En fin, espiritualidad de comunión es saber 'dar espacio' al hermano, llevando mutuamente la carga de los otros $(\mathrm{Gal} 6,2)$ y rechazando las tentaciones egoístas que continuamente nos acechan y engendran competitividad, ganas de hacer carrera, desconfianza y envidias. No nos hagamos ilusiones: sin este camino espiritual, de poco servirían los instrumentos externos. Se convertirían en medios sin alma, máscaras de comunión más que sus modos de expresión y crecimiento ${ }^{36}$.

\subsubsection{Formar para una espiritualidad de la caridad pastoral}

De nuevo aludimos al Documento de Aparecida: El presbítero...la caridad pastoral , fuente de la espiritualidad del sacerdote, anima y unifica su vida y ministerio. Consciente de sus limitaciones, valora la pastoral orgánica y se inserta con gusto en el presbiterio... (n.198).

Si es cierto que la santidad o perfección cristiana consiste en la caridad (LG,V), y la santidad o perfección sacerdotal consiste en la caridad pastoral (PO, 14), la caridad del Buen Pastor es el punto de referencia de toda espiritualidad sacerdotal (LG, 41). Caridad que mira a los intereses de la gloria

36 Cfr. Doc. Aparecida, cap. 5; Rivera Flores, R., La espiritualidad de comunión en una Iglesia Diocesana a la luz de Aparecida. México,2009, Cap I, pp.4-28. 
de Dios (línea vertical ascendente) y a los problemas de los hombres (línea horizontal). El equilibrio de estas dos líneas se encuentra en la misión y en la actitud de dar la vida (línea misionera). Para el sacerdote ministro esta caridad es un don de Dios (línea descendente).Por esto se hace unidad de vida personal y ministerial a la luz de la misión recibida $(P O, 14)$.

La caridad pastoral no es posible sin la relación personal con Cristo en la oración y especialmente en la celebración eucarística. La actitud de dar la vida resume toda la existencia de Jesús Buen Pastor. La fecundidad apostólica radica en esta entrega esponsal: En la cruz murió el Señor por las almas; hacienda, honra, fama y a su propia Madre dejó por cumplir con ellas; y así quien no mortificare su interés, honra, regalo, afecto e parientes, y no tomare la mortificación de la cruz, aunque tenga buenos deseos concebidos en su corazón, bien podrán llegar los hijos al parto, mas no habrá fuerzas para parirlos ${ }^{37}$.

La vida sacerdotal, precisamente por la actitud de caridad pastoral es vida martirial. Dar testimonio de Cristo supone sufrir por Él, con Él y como Él. La vida se hace martirio, se convierte en libación y oblación y en pan comido, cuando el sacerdote, a imitación de Cristo y en unión con Él, no se pertenece, sino que se da a sí mismo y vive como consorte o solidario de la historia de toda la humanidad. Entonces ya no se busca el propio interés, sino los intereses y amores de Cristo 38 .

Si el presbítero se configura como epifanía y transparencia de Jesucristo, Pastor de la Iglesia, habrá de de asimilar existencialmente y transparentar en su vida la caridad pastoral de Jesús con sus contenidos. Tales sentimientos, actitudes y comportamientos son actualizados por PDV teniendo en cuenta la situación actual y se ofrecen por lo mismo como los objetivos específicos de la formación del presbítero en este momento de la historia. Una simple enumeración de los mismos nos ofrece los siguientes:

* La formación de la sensibilidad del pastor, a la que ya hemos aludido (nn. 22,72 y 82),

* La donación de sí, la entrega sacrificial (n. 23);

* La actitud de servicio (nn. 21 y 58);

*El radicalismo evangélico (n.27) viviendo los consejos evangélicos como sacerdote: obediencia (n. 28), castidad célibe (n.29) y pobreza (n.30);

* El cuidado amoroso del rebaño, manifestado en la capacidad de relacionarse (n.43), el servicio de la caridad a los más pequeños ( $n$.

37 San Juan de Ávila. Obras Completas, IV, sermón 18.

38 La Caridad Pastoral. Materiales para la formación permanente- núm 3. Roma, 1998, 24-31. 
49), el diálogo (nn. 18,43,72), la comunitariedad y la colaboración (nn.17,23,26);

* Relación positiva y animadora de los laicos (n.17).

El Papa Juan Pablo II resumía justamente: El secreto de esta caridad pastoral se encuentra en el diálogo que Cristo mantiene con cada uno de sus elegidos, como lo mantuvo con Pedro... Así, por medio de este amor, confesado por tres veces, Jesús resucitado 'confió a Pedro sus ovejas'. Y del mismo modo os lo confía a vosotros. Es necesario que vuestro ministerio sacerdotal 'se enraíce con vigor en el amor de Jesucristo'39.

San Juan de Ávila, después de decir que allende de esta obligación que tiene de ser buen sacerdote, añade:

Y san Crisóstomo ponderando esto, dice que a quien se le encomiendan las almas le es encomendado el cuerpo místico de Jesucristo para que lo cure y fortalezca y lo hermosee con tantas virtudes que sea digno de ser llamado cuerpo de tal cabeza que es Jesucristo.

Y así el Señor manda a los pastores de las ovejas racionales que esfuercen lo flaco, que sanen lo enfermo, que aten lo quebrado, que reduzcan lo desecho y busquen lo perdido; para lo cual son menester muchas y muy buenas partes; porque no en balde dijo $S$. Gregorio: Ars artium, regimen animarum. Menester es mucha prudencia para saber llevar a tanta diversidad de gentes, y aplicar a cada uno su medicina según a cada uno conviene; menester es mucha paciencia para sufrir importunidades de ovejas sabias y no sabias, y que le dé Dios, como a Jeremías, una faz tan fuerte como diamante y pedernal, para que no sea vencido por amenazas $y$ malas obras de los que no consienten que los saquen de sus pecados, ni que los reprendan, ni que los curas hagan su oficio 40 .

La caridad pastoral resultante es la forma de todas las actividades y tareas del sacerdote (PDV, 23), e introduce en ellas una paternidad misteriosa pero real: las manos que dan el Pan y reconstruyen al pecador, actúan en el interior de las manos del Padre, escultor de lo más personal de cada persona justo cuando parece destruir la forma y abandonar la vida a la muerte. La caridad pastoral, amor al Señor en primer lugar, atrae al presbítero y lo conduce a ser capaz de amar a la gente con un corazón nuevo, grande y puro, con auténtica renuncia de sí mismo, con entrega total, continua y fiel, y, a la vez, con una especie de 'celo' divino (2Cor 11,2), con una ternura que incluso asume matices de cariño materno, capaz de hacerse cargo de los 'dolores

39 Discurso del 8 de noviembre de 1982.

40 En Escritos Sacerdotales, BAC, Madrid,1969, pp.174-175, Cfr. también p. 297. 
de parto', 'hasta que Cristo sea formado en los fieles' (Gal 4, 19) (PDV, 22$)^{41 .}$

\subsection{Para ser sacerdotes fieles}

Estimulados por una confianza vivida desde la fuerza del Evangelio, la caridad pastoral nos pide ser dispensadores fieles (1 Cor 4, 2) de la Palabra de Dios que se nos ha confiado. Esta fidelidad nos exige:

* Ser discípulos fieles de la Palabra de Dios desarrollando ya desde el Seminario nuestra condición de oyentes de esa Palabra y así superar la tentación de convertirse en funcionarios;

* Buscar el equilibrio necesario entre tradición y presente, contacto con las raíces apostólicas y con la situación de las comunidades a las que se sirve;

* Estudio serio y continuado para ser o llegar a ser maestros y guías de la fe de las comunidades, teniendo en cuenta que la formación continuada se ha de considerar como 'un acto de amor al pueblo de Dios a cuyo servicio está el sacerdote (PDV, 70);

* La Palabra de Dios ha de ir acompañada del diálogo con el mundo y sus habitantes: la misma caridad pastoral nos empuja a preocuparnos cada día más de las esperanzas, necesidades, problemas y sensibilidad de los destinatarios de nuestro ministerio, quienes se encuentran siempre en situaciones personales, familiares y sociales concretas (PDV,70);

* Responsable actitud al servicio de la pastoral para superar la tentación de situar el ministerio en un activismo buscado como fin en sí mismo, en una prestación impersonal de servicios, aunque sean espirituales y sagrados, o de reducirlo a una especie de funcionariado al servicio de la organización eclesiástica. Sólo la formación permanente ayuda al sacerdote a custodiar con amor vigilante el 'misterio' de que es portador para bien de la Iglesia y de la humanidad (PDV, 72). Principio de especial valor en la fase formativa del seminario y a tener en cuenta en las prácticas pastorales realizadas durante la misma 42 .

Sin duda este es un reto fundamental para cualquiera de las etapas formativas: la fidelidad para la misión (PDV, 75). Fidelidad que ha de prepararse en el seminario para que pueda madurar en el ejercicio del ministerio en medio de las dificultades que en él se presentarán y desde el cual dicha maduración ha de ser responsable y realista.

41 Cfr. Trujillo Díez, L., Diez miradas sobre el sacerdocio. Ciudad Real, 2002, 7-18.

42 Cfr. con mayor amplitud en Uriarte, J.M., Sacerdotes día a Día. Madrid, 1995,62-63. 
Porque siempre está presente el tema de cómo evangelizar. Y desde el seminario habrá que ir clarificando lo que significa nuevo ardor, nuevos métodos y nuevas formas de expresión. Pablo VI lo había formulado ya en la Evangeli Nuntiandi: el problema de cómo evangelizar es siempre actual, porque las maneras de evangelizar cambian según las circunstancias de tiempo, lugar y cultura; por eso plantean un desafío a nuestra capacidad de descubrir y adaptar ( E.N, 40).

Esto quiere decir, y nos lo recuerda ya PDV desde su comienzo, que es una exigencia la actualización, siempre desde una fidelidad creadora, que tenga en cuenta los destinatarios de la misión. Posiblemente esto no es tan necesario enfatizarlo en el Seminario porque los mismos alumnos son hijos de su tiempo, pero sí se nos exige cuidar donde y con quien hacen sus escarceos pastorales (Cfr. PDV, 5).

Esta fidelidad es la que debe arropar la caridad pastoral que en otro tiempo llamaban simplemente celo. Que fluye de la Eucaristía como enseña el Concilio Vaticano II $(P O, 14)$. De ahí que la misma fidelidad pide al seminarista y al presbítero estar íntimamente unidos al Señor para que pueda ser eficaz. Manuel Domingo y Sol, apóstol de las vocaciones, recordará que Jesús Sacramentado será indudablemente el móvil de nuestras operaciones. Por ello exhorta a la oración ya que sin ella es moralmente imposible la santificación del sacerdote y porque la oración es celo43.

Es lo que dirá el Concilio Vaticano II: A fin de cumplir con fidelidad su ministerio, gusten de corazón el cotidiano coloquio con Cristo Señor en esa visita y culto personal a la Santísima Eucaristía (PO, 18). Años más tarde lo subraya Juan Pablo II: El contacto con la Luz nos hace luminosos. La comunión con la Vida nos da nueva vida y hace de nosotros comunicadores de vida. Dejarse animar por la presencia de Dios, que actúa en nosotros, nos llena de un celo irreprimible e inagotable, que nos lleva a una constante actitud de servicio a los hermanos ${ }^{44}$.

Aparecida afirma que valoramos con gozo que la inmensa mayoría de los presbíteros vivan su ministerio con fidelidad y sean modelo para los demás (n.191) y PDV, refiriéndose a la formación permanente nos dice que su naturaleza profunda ha de considerarse como fidelidad al ministerio sacerdotal y como 'proceso de continua conversión' (n.70).

Juan Pablo II en su mensaje a los sacerdotes españoles, con motivo del $\mathrm{V}$ centenario del nacimiento de San Juan de Ávila, escribió:

Así, san Juan de Ávila, tanto en su vida como en sus escritos, nos ha enseñado que el sacerdote no sólo se forma para llegar a serlo,

43 Escritos I, 5, 31, 50 y 70.

4427 de enero de 1990. 
sino para ser fiel a la vocación recibida y a la continua misión a la que Dios sigue llamando ya en el ministerio, pues 'en realidad, Dios sigue llamando y enviando, revelando su designio salvífico en el desarrollo histórico de la vida sacerdotal y de las vicisitudes de la Iglesia y de la sociedad (PDV, 70). Juan de Ávila ha sabido ser fiel a esta vocación continua del Señor en la Iglesia y sociedad que le tocó vivir y ejercer en fraternidad su misión. Supo entender que esta misión había de hacerla en fraternidad con los demás evangelizadores y ayudando a despertar y aunar los diversos carismas en la lglesia45.

\subsection{Para acompañar y dejarse acompañar}

Tomemos de nuevo el Documento de Aparecida. Refiriéndose al itinerario formativo de los discípulos misioneros indica que la formación contempla el acompañamiento de los discípulos:

Cada sector del Pueblo de Dios pide ser acompañado y formado, de acuerdo con la peculiar vocación y ministerio al que ha sido llamado: el obispo que es el principio de la unidad de la diócesis mediante el triple ministerio de enseñar, santificar y gobernar ; los presbiteros, cooperando con el ministerio del obispo, en el cuidado del pueblo de Dios que les ha confiado; los diáconos permanentes en el servicio vivificante, humilde y perseverante como ayuda valiosa para obispos y presbiteros; los consagrados y consagradas en el seguimiento radical del Maestro; los laicos y laicas que cumplen su responsabilidad evangelizadora, colaborando en la formación de comunidades cristianas y en la construcción del Reino de Dios en el mundo. Se requiere, por tanto, capacitar a quienes puedan acompañar espiritual y pastoralmente a otros (n. 282).

No hace mucho tiempo, yo mismo recordaba algunas ideas sobre el tema. En efecto, creo que la dirección espiritual o acompañamiento entre los sacerdotes no está muy de moda y no es práctica generalizada. En un momento histórico y eclesial en que la espiritualidad presbiteral es de confianza y no de optimismo; de fidelidad y no de éxito, de servicio oscuro y de hacer sosegado, necesitamos aceptar el hecho de que nuestra connatural debilidad humana y religiosa exige dejarnos acompañar al mismo tiempo que estar preparados y disponibles para acompañar a otros.

Tiene el tema mucho que ver, por una parte con la amistad y, por otra con la dirección espiritual o acompañamiento. Pero pensando en el seminario y en la vida ministerial, creo que es muy necesario el aprendizaje para acompañar a otros al mismo tiempo que el desarrollo de la conciencia de la necesidad

45 Cfr. en Obras Competas, I, Apéndice V, p. 373. 
de dejarnos acompañar siempre.

Especialmente necesario el acompañamiento en un momento histórico en que la autoestima del sacerdote ha mermado notablemente en las sociedades más industrializadas, pues como dice el conocido autor Greshacke en su interesante libro Ser Sacerdote, para la gran masa, el sacerdote es una especie de agente comercial que no consigue colocar su producto ${ }^{46}$.

Se explica que este déficit de autoestima y valoración social genere tristeza, cierto sentimiento de culpabilidad, resentimiento y, en casos límite, el abandono del ministerio. Aunque es cierto que estas reacciones van unidas a otras causas, tanto la etapa de formación llamada inicial como la permanente debe ofrecer formación y espacios para la atención a la persona. La relación fraterna entre sacerdotes, la intercomunicación entre los seminaristas en los últimos años de su estancia en el seminario con los mismos sacerdotes y el obispo ha de ser un medio preventivo que, al mismo tiempo cultiva la necesidad de que debe continuarse durante el ejercicio del ministerio.

Ser sacerdotes y santos en medio del mundo es un milagro, repetía el citado Manuel Domingo y Sol. Y este milagro no lo podemos hacer solos. En el caso del sacerdote diocesano, desde el comienzo de su ministerio y a medida que avanza por su camino, crece la convicción de que el acompañamiento es una necesidad vital y constante. Alguien en quien confiar los imprevisibles movimientos de la existencia sacerdotal.

El llevar la dirección o acompañamiento espiritual con regularidad y el estar dispuesto a darla con generosidad lleva consigo un coste o mejor una inversión a precio de disciplina, constancia, abertura de corazón y preparación seria ya desde los años del seminario.

El acompañamiento de Jesús a sus discípulos tiene como razón última el encuentro y la aceptación del misterio y la respuesta con El para aceptar la voluntad del Padre. Por ello Jesús vuelve una y otra vez al tema en sus conversaciones a solas con los suyos, incluso después de resucitado. A través de palabras y gestos, de escucha paciente de sus deseos y aspiraciones; de explicaciones detenidas a veces por caminos polvorientos o senderos personales de desencanto. Va llevando a los suyos a entender verdades y recuperar esperanzas. Es el acompañamiento.

Después de Jesús, apóstoles, confesores, obispos han ejercido el acompañamiento, caminantes al lado del otro, conformándose incluso con que les dejen caminar a su lado algún trecho de su camino explicando o en silencio, como Back decía del acompañamiento a los adolescentes.

Desde esta perspectiva se rescatan los valores del acompañamiento evan-

46 Cfr. Ser sacerdote, Sígueme, Salamanca, 2003, 19-24. 
gélico y sacerdotal: la escucha, el cuestionamiento, la oferta de otras categorías con la que medir la realidad ministerial sin marginar el horizonte último del ministerio que emerge siempre al final de los relatos y que se constituye en clave interpretativa del mismo acompañamiento. En nuestro caso, la confrontación amorosa con Jesús de Nazaret con cuyo pastoreo nos hemos de configurar a lo largo de toda la vida sacerdotal 47 .

Sin olvidar que abriéndose y dejándose acompañar, el encuentro espiritual nos prepara a la apertura y al diálogo con el Señor. Pasamos del gusto por Dios a la amistad que nos hace gustar la confianza y la fidelidad. Y una vez gustada, hemos de prepararnos para saber celebrarla, porque la celebración es el último tramo de la amistad y de la misma vida ${ }^{48}$.

\subsection{Para situarse siempre como discípulos}

El Documento de Aparecida nos lo dice claramente en el capítulo dedicado a la formación de los discípulos misioneros anteriormente citado: La vocación y el compromiso de ser discípulos y misioneros de Jesucristo en América Latina y El Caribe, requieren una clara y decidida opción por la formación de los miembros de nuestras comunidades, en bien de todos los bautizados, cualquiera que sea la función que desarrollen en la Iglesia... Miremos a Jesús, el Maestro que formó personalmente a sus apóstoles y discípulos. Cristo nos da el método: vengan y vean... su estilo se vuelve emblemático para los formadores y cobra especial relevancia cuando pensamos en la paciente tarea formativa que la Iglesia debe emprender, en el nuevo contexto sociocultural de América Latina (n. 276).

El itinerario formativo del seguidor de Jesús hunde sus raíces en la naturaleza dinámica de la persona y en la invitación personal de Jesucristo, que llama a los suyos por su nombre, y éstos lo siguen porque conocen su voz. El Señor despertaba las aspiraciones profundas de sus discípulos y los atraía a sí, llenos de asombro. El seguimiento es fruto de una fascinación que responde al deseo de realización humana, al deseo de vida plena. El discípulo es alguien apasionado por Cristo, a quien reconoce como maestro que lo conduce y acompaña (n. 6,2).

Partimos de la idea de que la formación, inicial o permanente, no existe sin los discípulos. Por ello es imprescindible en todo itinerario formativo crear lo que algunos llaman un espíritu permanente de discípulo.

47 Comendador, J, F., Apuntes inéditos, México, 2008.

48 Rupnik, M., Alla mensa di Betania. Roma, 2005, 104 Cfr. Rubio Parrado, L., La Formación Permanente, como fidelidad al ministerio sacerdotal y como proceso de continua conversión. Seminarios sobre los ministerios en la Iglesia, 189-190 (juliodiciembre 2008) 146-148. 
No es tan fácil como parece, pues siempre acecha la tentación de dejar cuanto antes el ser discípulos para pasar a ser maestros. Sobre todo en la actualidad en que ser maestro se entiende como tener la última palabra, contar con una autoridad reconocida, tener más personalidad.

Pero no podemos olvidar, tampoco los seminaristas y los sacerdotes, que en la vida cristiana no se deja nunca de ser discípulo de Cristo. Ser discípulo es la condición del cristiano... Está muy claro en las enseñanzas de Jesús a sus discípulos: Vosotros, en cambio, no os dejéis llamar Maestro, porque uno solo es vuestro Maestro, y vosotros sois todos hermanos (Mt 23, 8).

El discipulado es, por otra parte, constitutivo de quien es sacramento de la mediación de Cristo, tal como se define al mismo sacerdote. Si lo propio de la sacramentalidad del ministerio ordenado es la referencia permanente a Cristo y actuar en su nombre (Mt 18, 19), también le es propio un discipulado permanente. Se refuerza lo anteriormente dicho por el hecho de que la mediación de Jesucristo es absoluta: Nadie va al Padre sino por mí (Jn 14,6); Sin mí no podéis hacer nada (Jn 15,4). Con estas afirmaciones del mismo Jesús, no tiene sentido que un sacerdote viva y actúe por libre, al margen de la mediación de Cristo. La conciencia de ser siempre discípulos debe acompañar al sacerdote en su ministerio y en su vida. Y para prepararla se debe incorporar en los planes formativos del seminario 49 .

\section{NOTAS PARA UN PROYECTO DE FORMACIÓN CONTINUADA}

Intentemos llegar a una síntesis. Teniendo presente que el seminario es el presbiterio de la diócesis en gestación, es muy importante que el candidato vaya conformando su persona con las actitudes de Jesús Buen Pastor y también asimile la dimensión fraterna del ministerio 50.

La asimilación ha de pasar por un aprendizaje si no queremos que luego fallen, como han fallado, tantos intentos, por ejemplo de equipos de vida o de vida y trabajo en las llamadas unidades pastorales en algunas diócesis.

Por ello, antes de salir al ministerio, deben los candidatos aprender a trabajar en unión con los demás (PDV, 21) en el seno de una comunidad cristiana especial, formada por los formadores y los seminaristas. Sólo así el seminarista educa su sentido comunitario y se prepara para dar el salto a la fraternidad presbiteral.

49 Cfr. Gamarra, S., Nuevo momento de la Formación Permanente, en Surge, 600 (2000) 58-63-

50 Blázquez Pérez, R., Eclesiología y espiritualidad de comunión. Edice, Madrid, 2003, 23-24. 
La vida comunitaria lo debe capacitar para establecer las relaciones de comunión propias de los presbíteros; la cooperación y obediencia sincera y cordial con el Obispo (OT, 9); la colaboración y fraternidad con los hermanos en el presbiterio del que van a formar parte después de la ordenación; de atención privilegiada a los enfermos, afligidos, cargados en exceso de trabajo y solidarios $(\mathrm{PO}, 8)$; el trato cercano y fraterno con los fieles, laicos y religiosos (PO, 11).

De este modo, el seminario formará futuros pastores aptos para adoptar diversas formas de colaboración y vida común y para ser constructores de comunidad (PO, 8).

Por ello, años más tarde de PO, la RFIS de 1970 subraya la importancia de crear estrechos lazos de unión entre seminaristas y sus propios obispos, a la vez que con el clero diocesano, basados en la caridad recíproca, diálogo frecuente y toda clase de colaboración (nn. 22 y 47).

Todo ello debe ser contemplado en un proyecto de formación continuada en el que además de los objetivos ya señalados, se parta como base ideológica o preámbulo, entre otros, de los siguientes presupuestos:

* Hacerse sacerdote es entrar en una comunión fraterna, íntima y sacramental, que vincula estrechamente a los ministros entre sí, pues están vitalmente unidos a Cristo;

* La fraternidad sacerdotal no es un lujo o un premio o algo privativo de un grupo privilegiado; es una vocación, un compromiso y, ante todo, un don. Por serlo, como toda gracia, hay que pedirla;

* No es un hecho natural, pero supone una serie de cualidades humanas y virtudes morales como la compasión, la paciencia, el perdón, la generosidad. Supone, por tanto, un serio compromiso ascético51.

* Hay que creer -y preparar para la fe- en la fraternidad, creer que es posible y desearla, como tantos sacerdotes que la han vivido a lo largo de la historia sacerdotal de la Iglesia: san Juan de Ávila, santo Tomás de Villanueva, san Juan María Vianney, san Juan Eudes, el cardenal Mercier, don Columba Marmión, el Beato Manuel Domingo y Sol para la Asociación Sacerdotal de los Sacerdotes Operarios Diocesanos, el P. Chevrier para la familia del Prado, el P. Rougier para quien nada del sacerdote nos debe ser extraño y lo dejó como herencia espiritual para su obra de los Misioneros del Espíritu Santo... y tantos otros que cada uno puede añadir en su catálogo personal y diocesano.

51 Cfr. Bertola, C., Fraternidad Sacerdotal. Editorial Atenas, Madrid, 1992, 117-120. 
* No persiguiendo la creación de un espíritu corporativo, sino creando medios para la promoción de la vida espiritual y de la renovación integral de los sacerdotes, como fuerza y ayuda para avanzar con mayor facilidad y dinamismo en el camino de la perfección tal como deseaba el hoy Beato Juan XXIII en su encíclica Sacerdotii Nostri Primordia del 1 de agosto de 1959 con motivo del centenario de la muerte del Santo Cura de Ars;

* Las Asociaciones sacerdotales, si se ponen al servicio de la comunión de todo el presbiterio y ofrecen una ayuda a la formación permanente de sus componentes, constituyen una auténtica riqueza y son otras tantas formas de ejercer la caridad pastoral;

* En el mismo seminario, hablando a los alumnos, hay que pasar de los presupuestos a las conclusiones; hay que pasar de la fraternidad comprendida a la fraternidad vivida, como algo propio del presbítero diocesano secular;

* Educar el sentir de los candidatos a que es el Espíritu Santo el que nos abre a la comunión fraterna y, por ello, la fraternidad es una gracia que acogemos y no una realidad que conquistamos. Sólo Dios puede realizarla en nosotros; sólo Dios puede ofrecérnosla como gracia: Él mismo Jesús se dirige al Padre para pedirla como don: Te pido que todos sean uno, Padre, lo mismo que tu estás en mí y yo en Ti Jn 17, 21).;

* Todo ello realizado en una Iglesia local, puesto que como se ha indicado, la Iglesia de Dios acontece toda ella en la Iglesia local, particular, diocesana. La fraternidad sacramental universal se realiza más intensamente en el presbiterio de la Iglesia local; y en torno al obispo, es donde toma forma y entidad la fraternidad sacramental tal como pide $\mathrm{PO}$ a los presbíteros (n.8);

* Fraternidad como la que creó Jesús y a la que instruía por el camino a sus seguidores y que tenía, entre otras, estas características:

- La fraternidad de la gracia: Jn 17;

- La fraternidad de la libertad: No llevéis oro, ni plata, ni dos túnicas... Mt 10,9ss, para no dar lugar a un grupo sedentario, acomodado, instalado, atesorando, acumulando o defendiendo cualquier clase de haber... libres, colgados como el Hijo Amado de la misericordia del Padre;

- La fraternidad del servicio: somos para servir;

- La fraternidad del martirio: al servicio de la plenitud en el amor: dar la vida;

- Fraternidad ofrecida: no es para mí; y apostólica; sacerdo- 
tes, religiosos y laicos, integrada 52 .

Los candidatos al presbiterio tienen que llegar a asumir la fraternidad presbiteral como un elemento fundamental en su proceso de formación.

Y, por tanto, tal elemento debe constar en todo proyecto formativo de una casa de formación sacerdotal, como ya indicó OT, 4 y recoge puntualmente PDV: la institución del seminario mayor, como lugar o tiempo óptimo de formación debe ser confirmada como ambiente normal, incluso material, de una vida comunitaria (n.60).

$Y$ debe proporcionar los medios para alcanzarla en todas las áreas formativas tal como señalan los documentos de la Iglesia y el mismo Código de Derecho Canónico: Se debe formar a los alumnos de modo que, llenos de amor a la Iglesia de Cristo...se adhieran al propio Obispo como fieles cooperadores y trabajen conjuntamente con sus hermanos; mediante la vida en común en el Seminario y los vínculos de amistad y compenetración con los demás, deben prepararse para una unión fraterna con el presbiterio diocesano, del cual serán miembros para el servicio de la Iglesia (c.245,2).

El papa Pablo VI lo había escrito en su encíclica Eccesiam Suam: Hace falta hacerse hermanos de los hombres en el momento mismo de querer ser pastores, padres y maestros. El clima de diálogo es la amistad. Más todavía, el servicio53.

\section{CONCLUSIÓN}

El papa Benedicto XVI convocó el Año Sacerdotal Especial para favorecer la tensión de los sacerdotes hacia la perfección espiritual de la cual depende sobre todo la eficacia de su ministerio... La misión tiene sus raíces de un modo especial en una buena formación.

Por ello concluye diciendo a los participantes en la Asamblea Plenaria de la Congregación del Clero que la conciencia de los cambios sociales radicales de las últimas décadas debe mover las mejores energías eclesiales a cuidar la formación de los candidatos al ministerio ${ }^{54}$.

En plena sintonía con lo que había dicho PDV en la primavera de 1992:

La Iglesia sabe que puede afrontar las dificultades y los retos de este nuevo periodo de la historia sabiendo que puede asegurar, incluso para el presente y para el futuro, sacerdotes bien formados, que sean ministros convencidos y fervorosos de la 'nueva evange-

52 Cfr. Cabezas Barba, J., La fraternidad. Retiro. Roma, 2008. Inédito.

53 Encíclica del 6 de agosto de 1964. AAS 56 (1964), 647. Citado también en PDV, 74. 
lización', servidores fieles y generosos de Jesucristo y de los hombres.

No ocultamos las dificultades (Tampoco las ha ocultado Benedicto XVI en su carta de convocatoria del Año Sacerdotal ni en su homilía de apertura del mismo). No son pocas ni leves, pero para vencerlas están nuestra esperanza, nuestra fe en el amor indefectible de Cristo, nuestra certeza de que el ministerio sacerdotal es insustituible para la vida de la lglesia y del mundo (n.10).

Volvamos al fundamento de nuestro tema. En algún tiempo la formación inicial se consideró como la formación por antonomasia. Pero hemos de tener en cuenta que la maduración personal, la estructuración humana y ministerial del presbítero es tarea de toda la vida. Es un proceso inacabado, más que algo conseguido. La formación permanente no es algo que viene después de la formación inicial, sino que la precede y hace posible. Es aquí desde y donde adquiere sentido y fundamento la formación inicial. La formación permanente constituye hoy, el horizonte de sentido de la formación inicial55.

Cristo es fiel. Si los sacerdotes son fieles, si el seminario es fiel, se puede esperar, después de un otoño de siembra y de un invierno de silencio fecundante, una primavera florecida que garantiza un estío de frutos maduros. Como el sínodo del otoño de 1990 hizo brotar la exhortación PDV en la primavera de dos años más tarde.

54 Discurso del 16 de marzo de 2009.

55 Cfr. Yusta, J., Formación en Diccionario del Sacerdocio. Madrid, Bac, 2005, 309-322. 